\title{
Synthetic mooring ropes for marine renewable energy applications
}

\author{
Weller Samuel ${ }^{1,{ }^{*}}$, Johanning L. ${ }^{1}$, Davies Peter ${ }^{2}$, Banfield S.J. ${ }^{3}$
}

${ }^{1}$ Renewable Energy, College of Engineering, Mathematics and Physical Sciences, University of Exeter, Penryn Campus, United Kingdom

${ }^{2}$ Marine Structures Laboratory, IFREMER (Centre Bretagne), France

${ }^{3}$ Tension Technology International, Eastbourne, United Kingdom

* Corresponding author : Samuel Weller, Tel.: +44 1326259414; fax: +44 1326370450 ;

email address : $\underline{\text { S.Weller@exeter.ac.uk }}$

\begin{abstract}
:
Synthetic mooring ropes have a proven track record of use in harsh operating conditions over the past two decades. As one of the main users of ropes for permanent mooring systems, the oil and gas industry has opted for these components because they possess performance characteristics and economies of scale which are in many respects superior to steel components. Given this accrued experience, it is unsurprising that several marine renewable energy (MRE) device developers have utilised synthetic ropes, motivated by the need to specify economical, reliable and durable mooring systems. Whilst these components are potentially an enabling technology for the MRE sector, this is a new field of application which can feature highly dynamic mooring tensions and consequently existing certification practices may not be directly applicable. Based on the expertise of the authors, this paper provides a state-of-the-art overview of synthetic ropes in the context of MRE mooring systems, including key information about aspects of specification (performance attributes, classification and testing) as well as application (installation, degradation, maintenance, inspection and decommissioning). It is the intention of this review to provide valuable insight for device developers who are considering using ropes in the specification of fit for purpose mooring systems.
\end{abstract}

\section{Highlights}

- Synthetic mooring ropes have a proven track record in the offshore industry. Favourable properties include high strength, compliance, low density and cost. They are potentially an enabling technology for marine renewable energy devices. Current certification and testing guidance doesn't fully cover this new application. Insight is provided into rope properties, specification and usage for MRE devices. 
Keywords : Synthetic mooring ropes, Marine renewable energy, Material properties, Classification and testing, Installation, operation and maintenance, Inspection

\section{Introduction}

Floating marine renewable energy (MRE) devices require permanent mooring systems which are able to keep the device on station whilst minimising the combined effects of wave, wind and current loads on the system. To-date the majority of MRE device concepts proposed are at the early stages of development (defined by Technology Readiness Levels 1-3 [1]) and only a few designs have reached pre-commercial development status following prototype sea trials (TRLs 7-8). Due to the lack of deployment experience and in the absence of specific guidance [2], predictably a cautious approach to mooring system design is currently adopted based on existing certification guidelines and recommended practices developed primarily for the offshore oil and gas industry (e.g. Refs. [3], [4] and [5]). The approaches to mooring system design contained within these documents are conservative because the consequences of mooring system failure range from interruption of operations to loss of life or environmental disaster. As a result large factors of safety are used in the specification of mooring components and often redundancy is built into the mooring system to prevent loss of stationkeeping ability in the event of mooring line failure [6]. Whilst the failure of a mooring line or anchor could lead to catastrophic loss of the MRE device (e.g. the Oceanlinx MK3PC system in 2010 [7]), the consequences of such an event occurring are generally lower for MRE devices and therefore reliance on existing standards could lead to mooring system designs which are unsuitable for this application. The capital cost alone of a mooring system represents a significant portion of the overall expenditure of the device (estimated to be up to $10 \%$ [8]), which is less easily absorbed by the revenue generated from the sale of energy compared to a fully operational oil or gas platform [9]. In order to ensure progress through the 'valley of death' stage of commercial development, MRE device developers must therefore balance the competing requirements of designing robust and reliable mooring systems whilst exploring pathways to reducing capital, operation and maintenance costs. Innovation and the use of alternative materials have been identified as two ways to achieve this goal [8] and [10].

Synthetic fibre ropes are potentially an enabling technology for the cost effective design of MRE mooring systems. To provide insight for device developers and operators, a pertinent review of several key aspects is provided in this paper, including performance and durability attributes, classification and testing, in addition to installation and decommissioning considerations. Since the first 
use of nylon ropes for towing applications in the 1950s and initial tests of aramid mooring ropes in the 1980s [11], synthetic ropes have been used in a wide range of demanding surface and subsea applications. Adoption of these materials has been driven by favourable cost, physical property and performance attributes and these criteria have become increasingly important for fossil fuel exploration in ultra deepwater $(>2000 \mathrm{~m}$ ). At these depths significant weight and cost penalties are incurred if steel mooring components such as chain and stranded wire rope are exclusively used [12]. Due to the prevalent use of synthetic materials in the offshore industry, several MRE device developers are known to have used, be currently using or considering using synthetic ropes including (but not limited to) Carnegie Wave Energy's CETO device, Pelamis Wave Power's P2 device, Ocean Power Technologies' PowerBuoy and the Hywind floating wind turbine [13-16]. Because the design requirements of MRE mooring systems are unique, detailed investigation, as well as offshore experience, will be required before widespread adoption and certification is realised for this new application.

\section{Specification}

\subsection{Synthetic ropes as mooring system components}

A significant number of spread mooring systems for vessels (e.g. Floating Production, Storage and Offloading; FPSO) and offshore platforms (e.g. Mobile Offshore Drilling Units; MODUs) utilise synthetic fibre ropes for large sections of mooring lines. Worldwide annual rope production is not easily quantified, but in 2004 it was estimated to be worth around $\$ 1.6$ billion [17]. The selection of these materials over steel chains and wires is motivated by several key factors. Synthetic materials display timedependent viscoelastic and viscoplastic behaviour (e.g. Figure 1) which is dependent on previous load history as well as the applied mean load, load amplitude (and to a lesser extent) load rate [18, 19]. Comparatively these materials display greater compliance or lower axial stiffness than steel components with non-linear, viscoelastic load-extension behaviour. They also possess the ability to absorb energy during cyclic loading (as described by Johanning et al. in Ref. [20]) and this is of particular importance in the case of rapidly applied snatch loads. In this scenario a component constructed from an inelastic material would experience much greater peak loads than one manufactured from a compliant material (e.g. differences of up to $20 \%$ were noted for a WEC configuration by Kirrane et al. in Ref. [21]). Under the application of a constant load, extension or 'creep' occurs, with recovery taking place if the load is reduced. These two mechanisms occur immediately or after a short delay and are indicated as (C) for creep and (D) for recovery in Figure 1. The initial loading of a newly manufactured rope will result in permanent extension (indicated as (E) in Figure 1), partly due to the viscoplastic response of the material but also due to rearrangement of the rope structure. Because of this, tension-tension tests usually commence with a number of 'bedding-in' cycles to allow ropes to be tested at a known state. During dynamic loading, energy absorption and dissipation (or hysteretic damping) are displayed, indicated as (B) in Figure 1.

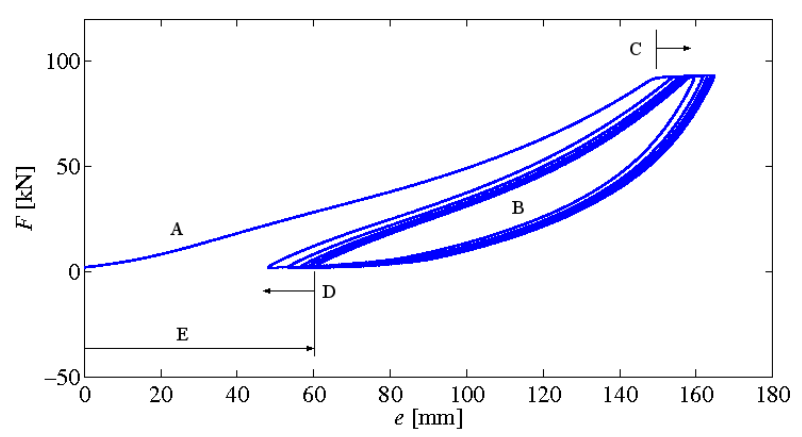

Figure 1: Load-extension behaviour of a new nylon mooring rope sample subjected to 10 cycles of bedding-in from tests reported in Ref. [18]. The occurrence of extension during initial loading (A), hysteresis during cycling (B), creep (C), recovery (D) and permanent extension (E) are shown.

Synthetic ropes do not suffer from corrosion problems and possess greater tension fatigue (e.g. Figure 2), out-ofplane loading and torsion performance than steel components $[22,6,10,23]$. Since 2001 several steel component failures have resulted in major permanent mooring incidents [24]. Indeed, the only fibre rope failure reported in Ref. [24] was caused by a significant increase in load due to the failure of two adjacent chains combined with the fact that the rope had been previously damaged by a steel wire $[25,26]$. Banfield et al. demonstrated experimentally in Ref. [27] that polyester ropes can have a fatigue life which was 50 times greater than steel wire rope. Furthermore synthetic materials have a lower density than steel and therefore lower capacity connecting hardware and structural bracing can be specified. This, combined with a typically low cost per unit length means that synthetic ropes can contribute to the design of economical MRE mooring systems, as highlighted for several layouts by Ridge et al. in Ref. [10]. Further component cost savings may be achievable through economies of scale for large scale array deployments comprising many 100s of MRE devices [28] and these layouts may also permit shared mooring and foundation infrastructure (e.g. Ref. [29]). 


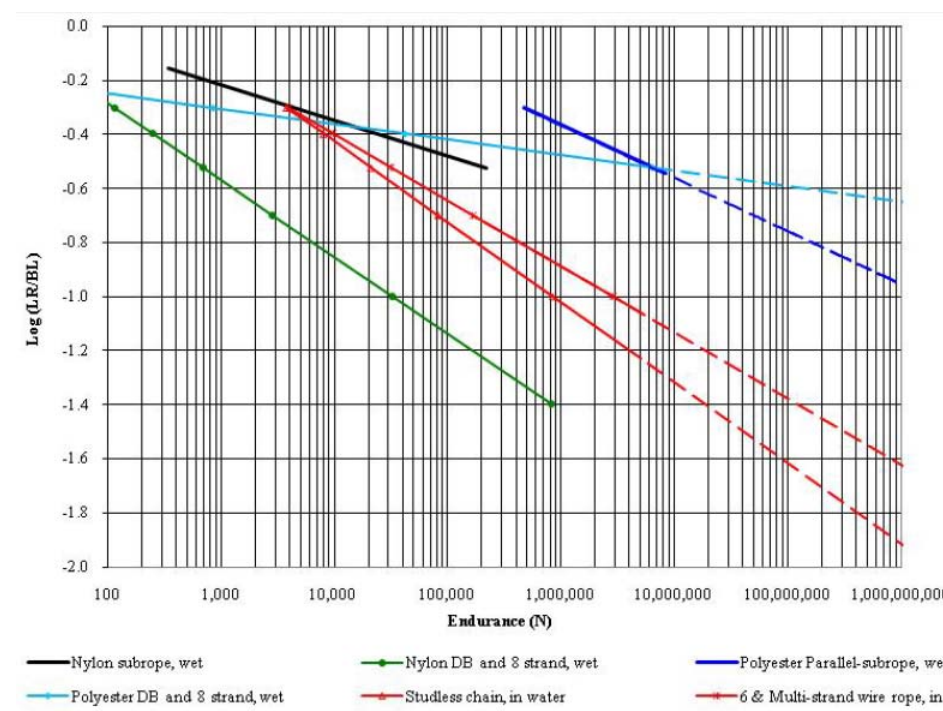

Figure 2: Example fatigue endurance results (from Ref. [10]) of several synthetic rope constructions, steel chain and wire for various load range to break load (LR/BL) ratios. Dashed lines indicate extrapolated values.

For spread catenary systems the low density of synthetic ropes necessitates the use of ground chains to provide sufficient horizontal and vertical restoring forces in order to keep the equipment on station. This configuration also prevents the ropes from coming into contact with the seabed which could result in abrasion of the outer rope strands unless protection is provided (as found on 'mudline' ropes [30]). Contact of the rope with the seabed is unlikely with a taut-moored system, in which ropes can be used for large sections of each line. The compliance of a catenary system is provided by the material properties of the mooring components and line geometry. The compliance of a taut-moored system is provided exclusively by line extension and hence this type of system allows for a lower range of horizontal and vertical device excursions than a catenary mooring system. Furthermore taut mooring lines may be susceptible to velocity induced vibration (VIV) in high flow environments, however long-term studies conducted for the oil and gas industry have concluded that this is not an issue for polyester ropes. For ropes constructed from high modulus materials the possibility of compressive strains occurring in terminations requires consideration at the design stage. The damping properties of synthetic ropes may mitigate the effects of VIV induced loading on fatigue wear, but this requires further study.

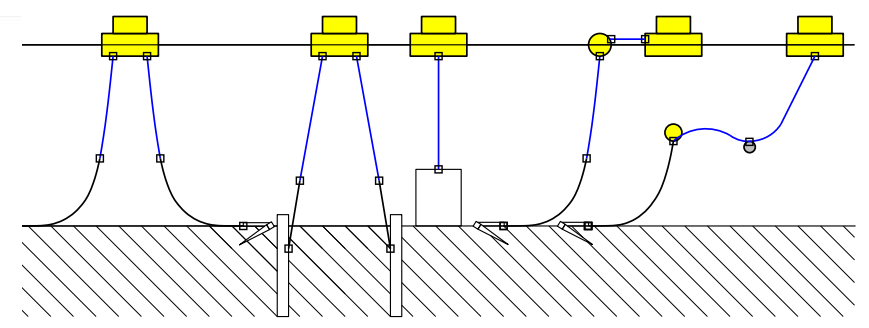

Figure 3: Schematic of possible MRE device catenary and taut mooring arrangements comprising synthetic ropes and chains (blue and black lines respectively). (For interpretation of the references to colour in this figure caption, the reader is referred to the web version of this paper.)

Of the numerous MRE device concepts which have been either been proposed or developed, most have included recognisable catenary or taut mooring configurations (or variants thereof [31]). Whilst conventional mooring system designs are broadly applicable to MRE devices (Figure 3), this is a new area of application in which the requirements of the mooring system are potentially very different from existing offshore applications due to: operating water depth, dynamic response characteristics, consequence of mooring line failure in addition to the mass and size of the moored equipment. Broadly MRE devices can be placed into two categories: i) devices which are reliant on a platform for stability and ii) devices where energy conversion is dependent on the motion of the entire device. The first category includes MRE devices comprising large floating structures, such as multi-use platforms (e.g. the Poseidon Floating Power Plant [32]). These devices have similar station-keeping requirements to offshore oil and gas equipment, which are designed to have natural periods which avoid environmental excitation in order to provide safe operating conditions (Figure 4). Whilst the requirement to keep the device on-station is also important for smaller structures such as floating tidal turbines (e.g. Scotrenewables' SR2000 [33]) the mooring systems of these devices are subject to significantly different loads and therefore the similarities between these two applications are limited. The second category includes motion-dependent devices such as wave energy converters (WECs). These devices are designed to have natural periods which correspond with dominant first-order wave excitation periods in order to maximise energy absorption for electricity production or water desalination. WEC responses which are close to resonant in one or more modes of motion may display complex motions [34, 35] and highly dynamic mooring system loads if there is strong devicemooring system response coupling [36, 20, 37]. Consideration of dynamic responses is especially important if the mooring system is an integral part of the power take-off system. Indeed it is possible that the mooring system could adversely influence energy extraction, or conversely it may be feasible to tune the response of a WEC by utilising synthetic ropes with particular attributes, such as 
axial stiffness and damping.

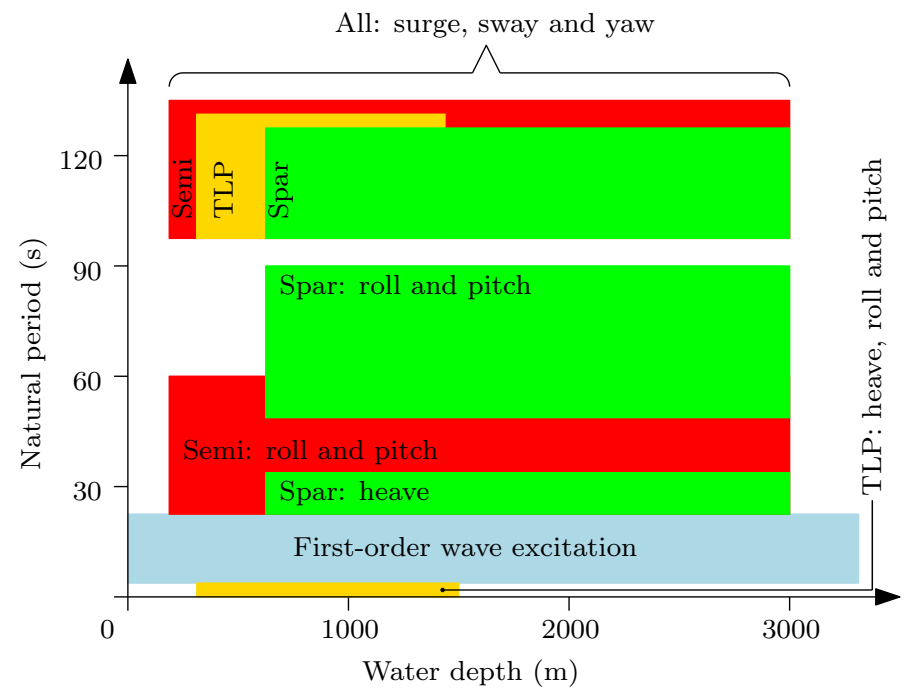

Figure 4: Indicative natural periods of spar, semi-submersible and tension leg platforms (TLPs). Values are taken from Ref. [38].

\subsection{Attributes}

Ropes have been manufactured for over two thousand years, with evidence of plant fibre constructions (i.e. flax and papyrus) used in Mesopotamia around 700 BC [17]. Widespread use of natural fibres persisted until DuPont, motivated by the need to achieve predictable fibre performance, invented nylon 6.6 in 1935. Commercial production of nylon 6.6 was bolstered by the demand for parachute cords and aircraft tyres during World War II [39] and in direct competition another polyamide, nylon 6 , was developed by IG Farben soon after. Following nylon, polyester was synthesised about ten years later with fibres commercialised by ICI and DuPont. Nylon and polyester are the most commonly used materials for mooring applications which require moderately high strength and ductility. Polyolefin ropes (polyethylene and polypropylene) are also used in some marine applications and possess similar stiffness characteristics to nylon and polyester, but have poor cyclic loading performance and are susceptible to ultraviolet (UV) light degradation. For taut-mooring applications which require components with a tensile strength comparable to steel but a significantly lower submerged weight, high modulus high tenacity materials (HM-HT) such as high modulus polyethylene (HMPE), liquid crystal polymer (LCP, e.g. Vectran(R) and aramid tend to be used. Copolymerisation or co-extrusion of several polymers (e.g. the combined extrusion of polypropylene and polyethylene) to obtain desirable performance characteristics have both received some attention, but few commercially available examples exist.
To provide a qualitative means of comparing the characteristics of synthetic materials, five materials which potentially could be used for MRE mooring applications are listed in Table 1, with typical stress-strain performance plotted in Figure 5. In comparison to steel these materials have very high strength to weight ratios (or tenacity) and are almost neutrally buoyant in seawater. In addition to reducing the pretension of the mooring system, the use of low density materials means that handling and lifting operations can be conducted with lower capacity equipment and smaller vessels. Based on extensive use in permanent and single point mooring (SPM) systems, it is likely that ropes constructed from polyester and nylon will be used for MRE mooring systems which require compliant mooring lines. Polyester absorbs very little water, however the strength of nylon reduces with water absorption, typically by around $10 \%[17,41]$. The structure of both materials is affected by elevated temperatures (above $200^{\circ} \mathrm{C}$ ), however this is unlikely to be an issue in offshore applications unless extreme localised heat generation occurs (discussed in Section 3.2). All of the polymers listed in this section are based on petroleum by-products and their production has an associated environmental impact. For example in order to synthesise nylon 6.6 adipic acid is used, the production of which involves the emission of nitrous oxide (a greenhouse gas). Whilst lower environmental impact methods of polymer synthesisation have been demonstrated (e.g. Ref. [42]) it may be some time before these production methods can be applied to the manufacture of fibres for offshore mooring ropes.

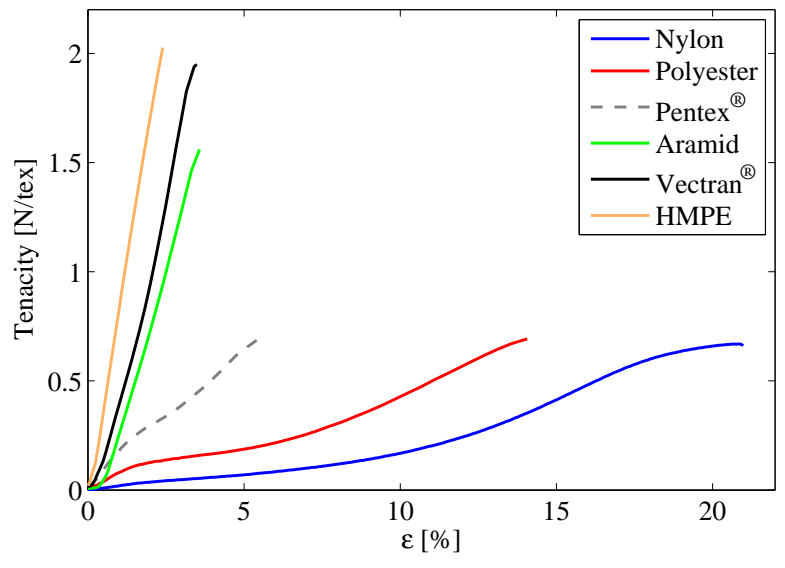

Figure 5: Comparison between typical fibre stress-strain behaviour. Note that these are families of available fibre types and the graph is based on tests conducted by the authors on low twist yarn samples. For each type various grades with a range of properties are commercially available.

Modern offshore mooring ropes are constructed from multi-filament yarns which are composed of twisted fibres ranging in diameter from 10 to $50 \mu \mathrm{m}$ (fibre diameters range from 0.2 to $0.5 \mathrm{~mm}$ for monofilament yarns [17]). The 


\begin{tabular}{|c|c|c|c|c|c|c|c|}
\hline & & $\begin{array}{l}0 \\
\Xi \\
0 \\
\vec{Z} \\
\vec{Z}\end{array}$ & $\begin{array}{l}\overrightarrow{0} \\
\frac{0}{0} \\
0 \\
\overrightarrow{0} \\
0 \\
0\end{array}$ & 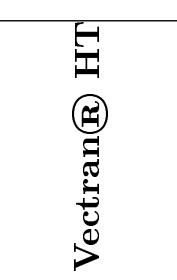 & 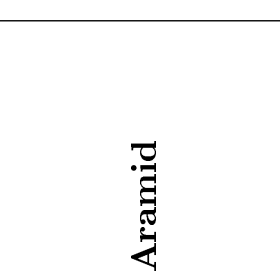 & $\sum_{i=1}^{|r|}$ & $\begin{array}{l}\vec{D} \\
\dot{D} \\
\mathbb{N}\end{array}$ \\
\hline \multirow{6}{*}{ 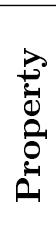 } & Density (g/cm^3) & 1.14 & 1.38 & 1.4 & 1.45 & 0.97 & 7.85 \\
\hline & Melting point $\left({ }^{\circ} \mathrm{C}\right)$ & 218 & 258 & 400 (chars) & 500 (decomposes) & 150 & 1600 \\
\hline & Modulus (N/tex) & 7 & 11 & 54 & 60 & 100 & 20 \\
\hline & Tenacity $(\mathrm{mN} /$ tex $)$ & 840 & 820 & 2286 & 2000 & 3500 & 330 \\
\hline & Break extension (\%) & 20 & 12 & 3.8 & 3.5 & 3.5 & 2 (yield point) \\
\hline & Moisture (\%) & 5 & $<1$ & $<0.1$ & $1-7$ & 0 & 0 \\
\hline
\end{tabular}

Table 1: Selected properties of synthetic materials which could potentially be used for MRE mooring systems, with steel included for reference (all values are from Ref. [17] apart from Vectran@ HT [40]. Moisture levels are specified at $65 \%$ relatively humidity at $20{ }^{\circ} \mathrm{C}$ (note: the modulus and tenacity of nylon 6 are lower when wet).

properties of synthetic materials used in fibre ropes include a wide range of stress-strain ranges. In Figure 5 Pentex(R) is also included because it has broadly similar properties to polyester (apart from a higher modulus) and may be used for mooring applications in the future [43]. Most ropes are constructed in hierarchical levels (e.g. fibres-yarns-yarn assemblies-strands-subropes-rope). Plaited and single or double braid constructions comprising $8 \mathrm{x}$ to $12 \mathrm{x}$ strands are widely used as they are straightforward to splice and are usually torque balanced to prevent twisting during loading. Constructions with a low helical twist angle are utilised for high load applications with multiple braided assemblies or subropes surrounded by a filtration screen and protective braided jacket to prevent abrasion or damage of the internal rope elements. Filtration screens have also been successfully used on braided 'mudline' ropes installed $30 \mathrm{~m}$ into the seabed [30]. Eye splices are typically used to terminate the rope and provide a means of connection to hardware such as shackles, thimbles and swivels, with a metal eye or protective sheath used to mitigate abrasion or rust contamination of the load bearing elements of the rope. To ensure that the load bearing elements of the rope share the load evenly, manufacturers follow standard design and test procedures for spliced terminations (e.g. Refs. [44, 45]).

Although there are clear differences in the performance of synthetic materials at a fibre level, construction also plays a key role in the characteristics of an assembled rope. This is illustrated by the load-to-failure tests of two new nylon constructions (double-braid and 8-strand plait constructions) reported in Ref. [17] in which significant differences between the break load, extension and axial stiffness characteristics of the samples were noted. Hybrid ropes are an extension of this idea, in which several constructions are combined (e.g. a parallel subrope core surrounded by a braid-on-braid outer) or alternatively fibres from two or more materials are used to construct yarns. Currently there are several novel constructions in the early stages of development that combine conventional rope making techniques with unconventional materials (e.g. elastomers) to provide favourable performance characteristics such as increased compliance. The Exeter Tether is one such construction which is in development and has been patented by the University of Exeter [46] with several prototypes manufactured in collaboration with Lankhorst Ropes for proof of concept testing [47].

\subsection{Classification and Testing}

To ensure that a mooring system is fit for purpose, the load bearing capacity and durability of all components (including synthetic ropes) must be sufficient for the expected operating conditions. The standard approach to mooring system design developed for the oil and gas industry can be found in certification guidance produced by agencies such as Det Norske Veritas, Bureau Veritas and the American Petroleum Institute (e.g. Refs. [3, 5, 4]). In Ref. [3] appropriate load safety factors are defined in terms of three scenarios: ultimate limit state (ULS), fatigue limit state (FLS) and accident limit state (ALS) and the respective consequence of a failure occurring. As mentioned in Section 1, the consequence of a loss of station-keeping ability for oil and gas exploration equipment is potentially more significant than the consequence of MRE mooring system failure. This crucial difference has been addressed in guidance produced for MRE devices through modified consequence criteria and limit states [48-51]. However because this guidance refers back to procedures developed for the offshore petroleum industry, this approach is still largely conservative and uncertainties exist regarding device dynamics and load cases as well as the contribution of component reliability to device availability [2]. Following a conventional approach to mooring system design could lead to the specification of systems for MRE devices which have high lifecycle costs and onerous maintenance requirements. This concern has prompted alternative approaches 
to be suggested, such as the use of standards developed for fish farms [9], however these may not be entirely suitable as this equipment is usually moored in sheltered locations. As highlighted in Section 2.1, this issue is further complicated by the variety of MRE device concepts proposed. It is likely that mooring system certification guidance for devices comprising large floating platforms will be similar to standards recently developed for floating wind turbines (e.g. Ref. [51]). Separate guidance will need to be developed for motion-dependent devices to cater for the unique load cases experienced by MRE mooring systems including the need for relevant limit states for devices with single mooring lines (e.g. CETO [13]). A shared approach to consequence based design may be possible for both MRE device categories, perhaps drawing upon the safety levels specified in Refs. [51] and [48].

Guidance documents for the use and testing of synthetic ropes have been developed over the past 25 years through several prominent joint industry projects (JIPs) and testing programmes, such as the DeepStar consortium [52], Norwegian and French projects [53]. Increased confidence in their use has led to safety factors being brought in-line with those specified for other mooring components. Generic guidance regarding manufacturing, quality control, testing, design and classification aspects can be found in Refs. [54, 44, 55, 45, 56-59], with guidance for more specific applications, such as SPM hawsers also available (e.g. Ref. [60]).

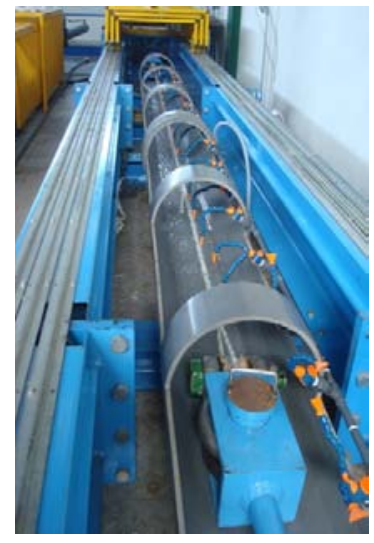

(a)

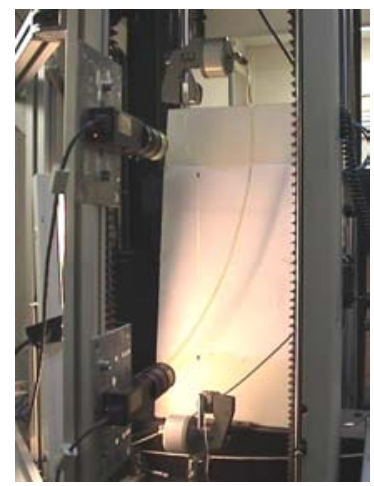

(c)

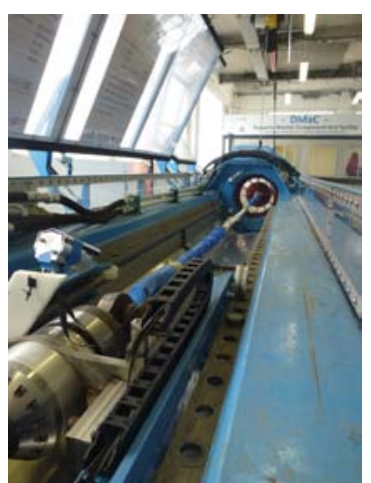

(b)

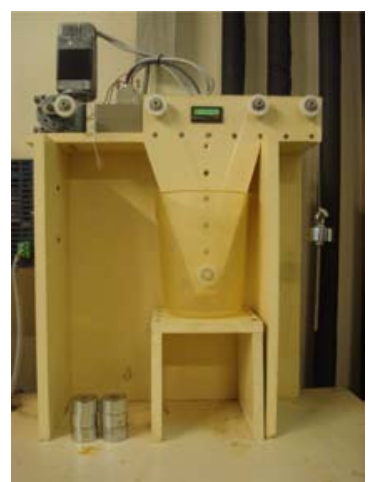

(d)
Figure 6: Examples of tension testing machines: a) IFREMER 100 Tonne machine, b) Dynamic Marine Component (DMaC) test facility and c) INSTRON $(\mathrm{B}$. machine with videoextensometry system. d) Yarn-on-yarn abrasion testing machine.

The majority of synthetic rope tests are conducted by research institutes and rope manufacturers using tensiontension machines. This equipment enables the load bearing capacity as well as operational and fatigue performance of rope samples to be determined in a controlled laboratory environment (e.g. Figure $6 \mathrm{a}$ and b) with tests conducted either dry or wet. In the latter case, following a period of soaking samples are either sprayed with water during testing or submerged (i.e. the Dynamic Marine Component (DMaC) test facility; Figure 6b). Smaller tension testing equipment is used for yarn and fibre testing (e.g. Figures $6 c$ and d). The principle rope tests which are used to define rope characteristics and long-term performance are outlined in guidelines such as API RP 2SM [44] (listed in Table 2). Similar test procedures can be found in the DNV-OS-E303 guidelines [45] which also include performance characterisation based on 3-Ts: tension, time and temperature. Of particular interest to the design of MRE mooring systems is the load-extension behaviour of the sample subjected to static or dynamic loading, because the axial stiffness of each rope will contribute to the total compliance of the mooring system. Sample extension is usually measured directly using a linear or pull-wire trans- 


\begin{tabular}{|l|l|}
\hline Load bearing capacity & Torque and rotation \\
\hline Static load-extension & Axial compression fatigue \\
\hline Dynamic load-extension & Creep and relaxation \\
\hline Tension-tension fatigue & \\
\hline
\end{tabular}

Table 2: Synthetic rope test aspects defined in API RP 2SM [44]

ducer clamped to the free length of the rope in-between the splices. Load-to-failure (or break) tests are conducted on samples in order to determine the minimum break load (MBL) of the rope [54, 61, 44].Despite slight differences, all break test procedures commence with at least one beddingin cycle up 50\% MBL before being loaded until failure at a constant load rate. To avoid equipment damage, it is not possible to directly measure extension of the sample during failure tests and instead a video-extensometry system must be used (e.g. Ref. [62]). To represent in-service aging, dynamic load tests are conducted to determine the tensile and compression fatigue life of components. The widely used thousand cycle load level; TCLL test procedure [60] comprises 1000 load cycles at several load levels, starting at a load range of 2-50\% MBL. Yarn-on-yarn cyclic tests are also conducted to determine the effectiveness of friction-reducing marine finishes $[63,10]$ using the equipment shown in Figure 6d). In addition, experimental studies such as those conducted by Derombise et al. [64] and Weller et al. [65] have investigated the long-term behaviour of seawater-aged fibres, focusing on aramid and nylon respectively. In Ref. [64] accelerated tests were conducted at different temperatures with results integrated into a creep model [66]. Comparative dynamic tensiontension rope and accelerated yarn-on-yarn tests were conducted on new and aged samples in Ref. [65] to investigate the effect of aging on component performance and durability.

Due to the non-linear, transient nature of rope responses, the selection of loading regimes used to characterise the behaviour of samples is non-trivial and must be representative of the stochastic loads expected in service [67]. Hence, the standard practice of applying thousands of harmonic load cycles to samples in order to determine material properties or to inform fatigue life calculations is debatable for MRE applications in which device responses and mooring loads are highly irregular (of varying amplitude, phase and mean load). An alternative approach could be the application of load cases based on measurements recorded in-service [68, 18, 65]. Certification guidance such as $[44,3]$ specifies the use of non-linear load-extension characteristics in mooring system analyses. Whilst this can be implemented in most commercial simulation packages, this will not fully account for the viscoelastic, viscoplastic and timedependent response of ropes, including hysteretic damping which may be necessary for MRE mooring system analyses [36, 20, 69]. For increased accuracy, such software must be coupled with sophisticated modelling tools (e.g. Ref. [70]) or look-up tables which comprise rope properties for different loading conditions. As part of FLS analyses, damage accumulation methods (such as the Pålmgren-Miner rule) are commonly used with fatigue life curves (i.e. Figure 2) to estimate the remaining life of the component for a given set of expected loading conditions. Fatigue curves and curve parameters are available for materials in general use (e.g. the creep of HMPE [54, 44], as well as the tensile fatigue life of polyester [27, 3] and nylon [10]. The applicability of Miner's summation to nylon ropes is the subject of ongoing studies. The test programmes conducted to-date have demonstrated that the scatter in rope properties is typically insignificant during the useful life of the component and only increases at the very end of its life (i.e. beyond retirement, as discussed in Section 3.3). For example, during the study reported in Ref. [27] repeated tests on polyester samples displayed very low coefficients of variation (from 6 to $39 \%$ which is very low for repeated fatigue tests), with similar findings noted for nylon samples in Ref. [10]. It is acknowledged that rope constructions featuring high helix angles, inadequate marine finishes or those subject to particulate ingress will be susceptible to high internal wear and thus rope property scatter can become large.

\section{Application of Synthetic Ropes}

The correct utilisation of synthetic ropes is critical for their long-term durability and load bearing capacity. In this section information is provided to aid the planning of installation, maintenance and decommissioning procedures.

\subsection{Installation}

During installation efforts should be made to mitigate the risk of rope damage occurring due to exposure to extreme temperatures, degrading chemicals, foreign particulates, UV light as well as cuts or abrasion caused by contact with auxiliary equipment. The susceptibility of synthetic ropes to these mechanisms is discussed in the next section. The installation of synthetic mooring ropes as part of a device deployment or recovery will require careful planning, with contingency factored in for unexpected events, including the failure of equipment and sudden weather or sea-state changes. Although the procedural requirements 
for MRE installations are unique and device specific, it is prudent to refer to existing storage, handling, transportation and installation guidance produced for the offshore industry (e.g. Refs. [44, 54, 45, 3]). For example, the use of staggered deployments, such as pre-laying and 'buoying off' the mooring system [71] prior to device deployment to reduce weather window vulnerability. Remotely operated underwater vehicles (ROVs) can be used to monitor rope twist and line straightness during line spooling [6]. As highlighted in Section 2.1, the structure of a newly manufactured rope will rearrange when it is first loaded. To settle the rope structure and therefore prevent permanent extension of the rope occurring in-service (which could lead to a detrimental reduction in mooring system stiffness) it will be necessary to carry out bedding-in during deployment because it is unlikely that MRE devices will have integrated re-tensioning equipment. The process of pre-tensioning using an anchor handling vessel could be carried out during anchor or foundation installation, for example during drag anchor embedment (as illustrated in Figure 7).

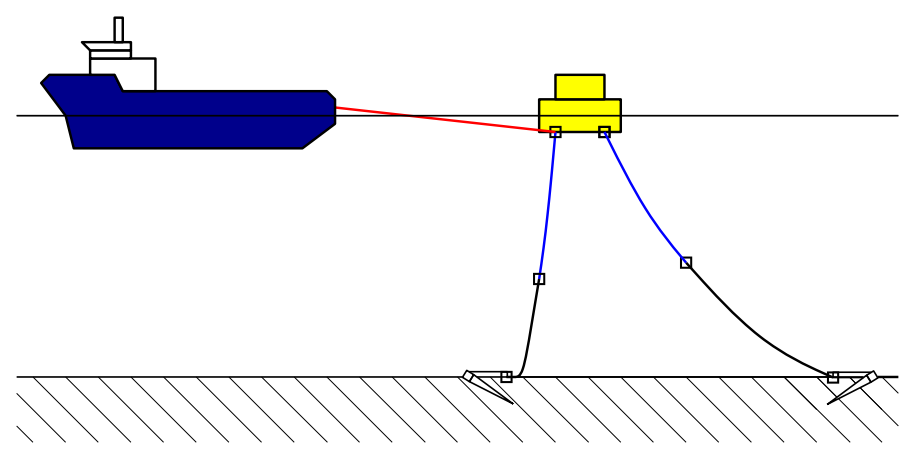

Figure 7: Schematic of fibre rope (blue line) pre-tensioning procedure carried out with an anchor handling vessel and detachable chain (red line). (For interpretation of the references to colour in this figure caption, the reader is referred to the web version of this paper.)

\subsection{Degradation mechanisms}

The structural properties of synthetic rope will evolve over time and these changes are dependent on a number of factors, including load history (and mode of loading), environmental exposure and handling. As summarised in Table 3 certain materials are more durable with respect to particular degradation mechanisms than others. There are several well-studied mechanisms [72, 17] which can potentially reduce the operational lifetime of synthetic ropes and contribute to a loss in residual strength: fatigue (tension and compression), particulate ingress and abrasion, hysteretic heating, UV light, creep, wet/dry cycling and snatch loading. Predicting the long-term effects of these mechanisms is key to assessing component reliability. In addition to the FLS analysis techniques introduced in Section 2.3, a number of complex modelling tools have been developed to investigate several rope degrada- tion mechanisms including; constitutive models, springdashpot-ratchet or slider models and finite element models (see Table 3.2). To-date these approaches have been mainly used in isolation and a limited number of studies have been published which have demonstrated integration with sophisticated mooring analysis tools (e.g. Ref. [70]).

Tension-tension fatigue is an effect caused by wear occurring due to friction between adjacent fibres during repeated load cycling $[77,65]$. The ingress of particles of grit, debris and marine species into the rope structure will accelerate wear from fibre-on-fibre friction and even fibre cutting may occur if hard-shelled species (e.g. mussels, limpets and barnacles) are able to penetrate inside [72]. Certain rope constructions comprising stiff materials (such as aramid and to a much lesser extent HMPE) are susceptible to compression fatigue occurring during low or zero loads. In this situation unloaded fibres buckle and become fatigue concentrations if the buckling point is flexed regularly. Abrasion or snagging of strands or yarns caused by the rope rubbing against other components or hardware can be prevented by the use of non-load bearing woven jackets or polyurethane coatings (which also provide a smooth surface preventing the adhesion of marine growth). Gradual extension through creep could result in the station-keeping abilities of the mooring system to be reduced and this phenomenon has been studied for materials such as polyester [80]. In extreme cases creep can result in the failure of HMPE ropes [75], however new grades have been developed with reduced creep characteristics [81]. Mooring ropes which are partially submerged will be subjected to wetting and drying cycles (i.e. the surface buoy line shown in Figure 3) and a build up of salt crystals could be an abrasive medium between contacting fibres, reducing the fatigue performance of the rope [82]. The development of marine finishes and micron-level filtration screens (to prevent the ingress of abrasive material $[83,84])$ have led to significant increases in the fatigue performance of synthetic ropes [30]. It is therefore recommended that these are considered for MRE mooring applications. Internal heating is caused by the hysteretic response of viscoelastic materials and slip occurring between fibres. When the rate of heat transfer from localised 'hot spots' to the exterior of the rope is insufficient the properties of the fibre will change and in extreme cases peeling of the fibre surfaces and melting can occur [77]. Research conducted by the offshore petroleum industry has suggested that this may be an issue for large diameter ropes subjected to large strain ranges $[85,76]$. In the case of highly dynamic device motions, it is possible that mooring components will experience localised heating through snatch loading especially if the mooring lines are temporarily slack (i.e. the leeward lines of a moored device). The effect of snatch loading on synthetic materials has been well studied for other applications (including parachute cords [86], aircraft arresting systems [87] and recreational uses such as climbing and sailing [88]) and 


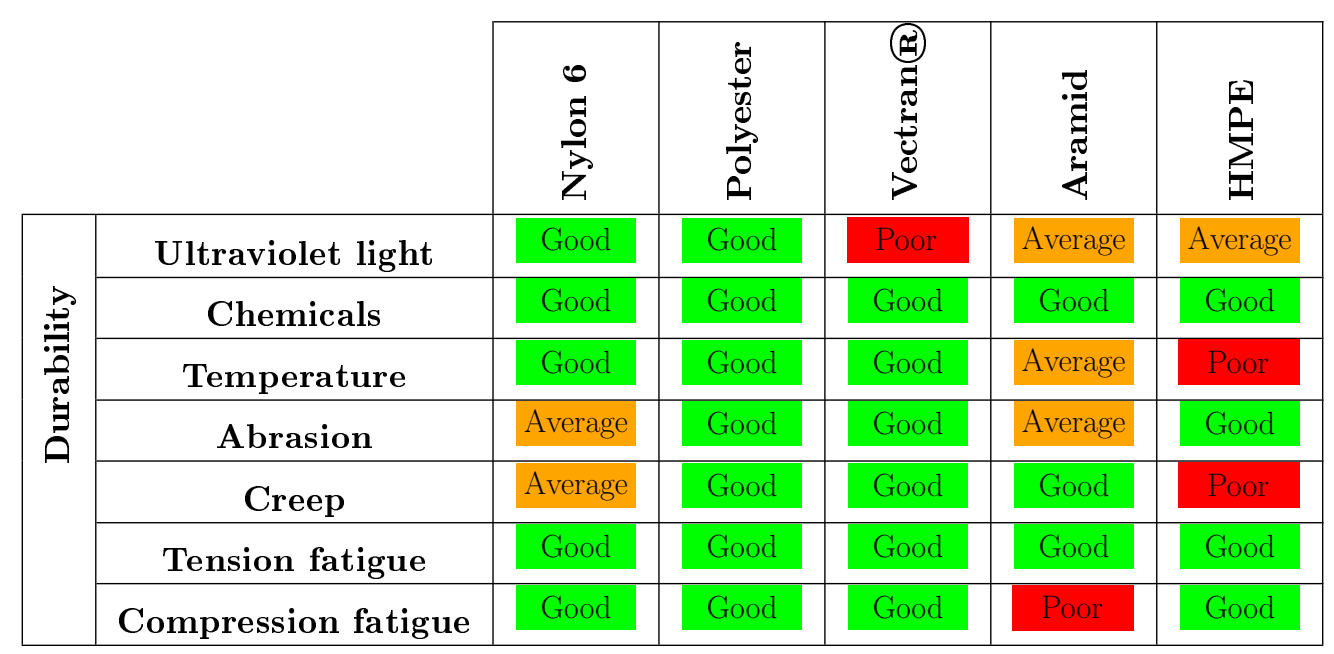

Table 3: Indicative durability of synthetic materials which could potentially be used for MRE mooring systems. The classifications; good, average and poor are taken from Refs. $[17,10,44]$ and author experience (note: actual performance will depend on the rope construction and application).

hence occasional snatch loading should not result in damage provided that the working load limit of the rope is not exceeded.

\subsection{Maintenance, inspection and decommissioning}

Compared to chains and connecting hardware such as swivels, synthetic ropes are relatively maintenance-free if used correctly. Many different fibre rope mooring systems such as riser arch tethers (aramid and polyester), riser protection nets (aramid, HMPE and polyester) and mooring systems (polyester) have been in use for 20 years. Tests conducted on fibres from such systems after 12 years of service have demonstrated $96 \%$ residual strength and fibres used for several years have shown $100 \%$ residual strength [89, 90]. As part of a wider condition management programme for offshore equipment mooring systems $[3,91,92]$, synthetic ropes are periodically inspected to assess if any damage has been sustained and to quantify residual life [45, 93, 94]. For synthetic ropes used in MRE applications, inspection intervals will depend on the material used and the loading conditions experienced by the mooring system. Detailed maintenance and inspection guidance for MRE devices has yet to be formulated and instead current certification guidelines either refer back to existing standards [48] or provide general advice on suitable intervals based on fatigue life calculations [49, 95]. Although developed for the offshore oil and gas industry, the DNV-RP-E304 Damage assessment of fibre ropes for offshore mooring guideline [94] and CI 2001-04 International Guideline. Fiber Rope Inspection and Retirement Criteria [93] provide comprehensive guidance on inspection procedures in the context of fatigue and damage mechanisms. Whilst a variety of approaches have been proposed for in-situ condition monitoring of internal rope elements
$[96,97,71,98,99]$, so far only prototypes have been trialled. In the first instance inspections are limited to visual checks using ROV equipment (and/or divers) with the lines in-situ or during line spooling. Clearly this only provides limited insight into the external condition of eyes, splices and load bearing components (such as bulging, wear through abrasion, cutting or chafing), and therefore internal damage could be hidden by marine growth or the protective jacket (if present). For MRE applications marine growth will not directly affect mooring ropes (unless hard-shelled species penetrate the rope interior), however a build-up of growth will increase the weight and drag of each line [3] which could adversely influence the response of the device. For this reason in latitudes where marine growth could be an issue, mitigation techniques for prevention (such as anti-fouling coatings [100]) or periodic removal may be necessary.

DNV-RP-E304 states that if damage is observed from visual checks then the rope must be recovered onto the deck of the work vessel for closer inspection. For tautmoored configurations a dive team would have to be used to disconnect the lower end of the line. For catenary configurations it may be possible to inspect the ropes if there is sufficient slack in the mooring lines (i.e. at low tide) without disturbing the anchors. For jacketed ropes, removal of the jacket (and filter if applicable) to inspect the internal rope components is only advised if protective measures can be reinstated prior to re-deployment. A methodology for estimating the remaining fatigue life and strength of ropes based on logging the number and scope of damaged load bearing components is outlined in Ref. [94]. A more explicit method to determine the residual strength of a rope is to carry out destructive testing on a sample length [93], such as load-to-failure tests or yarn-on-yarn abrasion testing [63]. By comparing with other rope components 


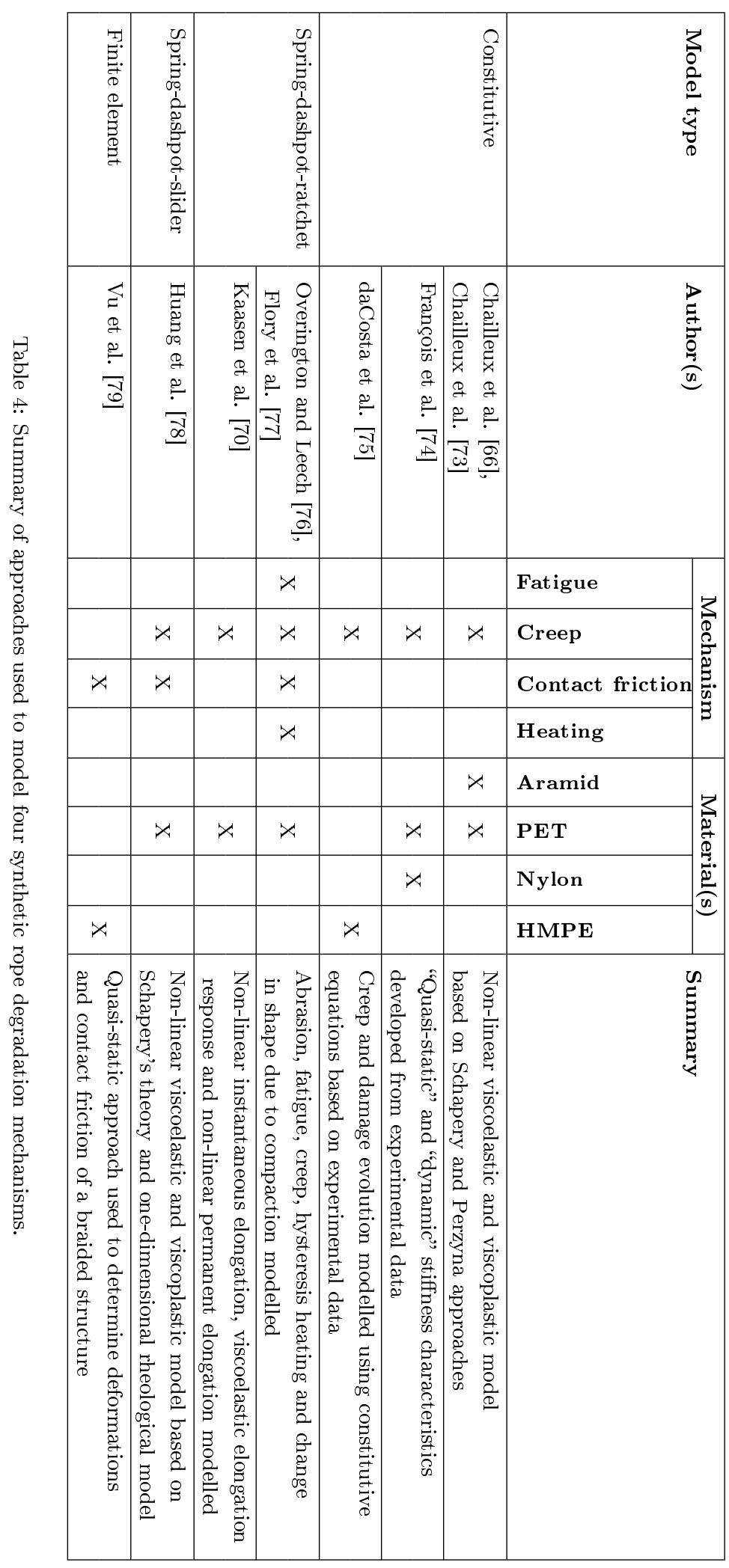

used in a similar application or new samples [65], destructive testing enables estimates to be made on the long-term durability of components as well as informing the development of numerical modelling tools. For MRE array installations comprising many devices, periodic line removal will be unfeasible due to the prohibitive costs associated with chartering appropriate vessels and the dependency of operations on favourable weather windows. Instead, as part of an on-going reliability monitoring programme [95], it is likely that a combination of load monitoring and visual ROV inspections will be used for lifetime calculations for most lines in the array. Line removal will therefore be limited to the areas of the array which are subjected to the brunt of environmental loading, at periodic intervals (e.g. every $5,10,15$ or 20 years).

If significant damage has been identified and repair is not possible, then it is necessary for the rope to be downgraded to a lower working load limit or taken out of service. The DNV-OS-E303 standard states that disposal is also necessary if loads exceeding $70 \% \mathrm{MBL}$ have been measured in-service [45]. Methods for decommissioning MRE installations are defined by local regulations, for example in the United Kingdom complete removal and proper disposal is favoured [101]. To reduce the environmental impact of synthetic materials, used ropes should ideally be recycled at the end of their service life, and well-established methods exist to recover energy or reuse nylon and polyester waste [102]. Currently Lankhorst Euronete is the only manufacturer which operates a recycling initiative [103] and this is probably because the recycling process can be difficult (due to contamination) and the fact that a large number of ropes are still currently being used.

\section{Conclusions}

In order for the nascent MRE industry to reach a stage of maturity where the strike price for generated electricity is competitive with other forms of generation, pathways to reducing capital, operating and maintenance costs must be sought. To ensure continuous generation capability, floating devices require mooring systems comprising low cost components which are suitable in terms of capacity, durability and reliability. Given that synthetic ropes have been used extensively offshore often in very demanding applications, they have the potential to be an enabling technology in the specification of fit for purpose MRE mooring systems. Indeed, monitoring of permanent mooring system components by the offshore oil and gas sector has highlighted issues regarding the long-term durability of steel components largely due to environmental exposure and fatigue loading. Synthetic ropes offer superior performance in these two aspects as well as providing peak load mitigation properties. 
For MRE devices requiring compliant mooring systems, it is likely that low modulus materials such as polyester and nylon will be used, with higher modulus materials such as HMPE, LCP and aramid used for taut-moored applications. In addition to the range of rope constructions commercially available, novel constructions are in development with efforts underway to determine the performance and long-term durability of these components. Considerable research has been conducted over the past two decades to determine the long-term performance of synthetic ropes through comprehensive test programmes and numerical model development, setting a precedent which has enabled confidence to be gained in their use as safety critical components. Some of this knowledge including particular guidance provided by offshore certification procedures is transferable to MRE mooring systems; however there are notable differences with this new application requiring careful consideration. Given the current state of the MRE sector it is understandable that a cautious approach to mooring system design which is reliant on practices developed for the oil and gas industry has been adopted. However to ensure that suitable MRE mooring systems are designed, specific testing and certification procedures need to be established which address the fundamental differences between these two applications.

\section{Acknowledgment}

This paper stemmed from research conducted as part of the Marine Energy in Far Peripheral and Island Communities (MERiFIC) project, funded by the European Regional Development Fund through the Interreg IV-A programme.

[1] J Fitzgerald and B Bolund. Technology Readiness for Wave Energy Projects; ESB and Vattenfall classification system. In Proceedings of the 4 th International Conference on Ocean Energy, Dublin, Ireland, 2012.

[2] J Wolfram. On Assessing the Reliability and Availability of Marine Energy Converters: The Problems of a New Technology. In Proceedings of the Institution of Mechanical Engineers, Part O: Journal of Risk and Reliability, 2006.

[3] Det Norske Veritas. Offshore Standard - Position Mooring. DNV-OS-E301. 2013.

[4] American Petroleum Institute. Recommended Practice for Design and Analysis of Stationkeeping Systems for Floating Structures. Third Edition. API RP 2SK. 2005.

[5] Bureau Veritas. Classification of Mooring Systems for Permanent Offshore Units. NR493DTR02E. 2012.

[6] Noble Denton Europe Limited. Floating production system JIP FPS mooring integrity. Research Report 444 prepared for the Health and Safety Executive. 2006.

[7] ABC News. Huge swell sinks wave energy generator. http://tinyurl.com/pofqvu5, May 2010. [Accessed online: 08/02/2014].

[8] Carbon Trust and Black \& Veatch. Accelerating marine energy. The potential for cost reduction - insights from the Carbon Trust Marine Energy Accelerator. 2011.

[9] GM Paredes, L Bergdahl, J Palm, C Eskilsson, and FT Pinto. Station keeping design for floating wave energy devices compared to offshore oil and gas platforms. In Proceedings of the 10th European Wave and Tidal Energy Conference, Aalborg, Denmark, 2013.
[10] IML Ridge, SJ Banfield, and J Mackay. Nylon Fibre Rope Moorings for Wave Energy Converters. In Proceedings of the OCEANS 2010 conference, Seattle, USA, 2010.

[11] I Corbetta and F Sloan. HMPE Mooring Line Trial for Scarabeo III. In Proceedings of the Offshore Technology Conference (OTC 13272), Houston, USA, 2001.

[12] GP Foster. Advantages of Fiber Rope Over Wire Rope. Journal of Industrial Textiles, 32:67-75, 2002.

[13] reNEWS. Carnegie seals $\$ 20 \mathrm{~m}$ for Ceto 6 . http://tinyurl.com/obeahkm, February 2015. [Accessed online: $22 / 02 / 2015]$.

[14] reNEWS. Pelamis hits 10,000 hours. http://tinyurl.com/nke8q9z, June 2014. [Accessed online: $15 / 06 / 2014]$.

[15] Ocean Power Technologies. OPT Newsletter. New Year 2015, 2015.

[16] Xodus Group Ltd. Hywind Scotland Pilot Park Project EIA Scoping Report for Statoil Wind Limited. Document number: A-100142-S00-REPT-001, 2013.

[17] McKenna, HA and Hearle, JWS and O'Hear, N. Handbook of Fibre Rope Technology. Woodhead Publishing Limited, Cambridge, UK, 2004.

[18] SD Weller, P Davies, AW Vickers, and L Johanning. Synthetic Rope Responses in the Context of Load History: Operational Performance. Ocean Engineering, 83:111-124, 2014.

[19] JF Flory, SJ Banfield, and DJ Petruska. Defining, Measuring, and Calculating the Properties of Fiber Rope Deepwater Mooring Lines. In Proceedings of the Offshore Technology Conference (OTC 16151), Houston, USA, 2004.

[20] L Johanning, GH Smith, and J Wolfram. Measurements of static and dynamic mooring line damping and their importance for floating WEC devices. Ocean Engineering, 34:1918-1934, 2007.

[21] Kirrane, P and Fabricius, P and Morvan R. Development of an Efficient Design Technique for the Optimisation of Mooring Systems for Wave Energy Arrays. 2010.

[22] S Banfield, T Veravel, RO Snell, and RV Ahilan. Fatigue Curves for Polyester Moorings - A State-of-the-Art Review. In Proceedings of the Offshore Technology Conference (OTC 12175), Houston, USA, 2000.

[23] Det Norske Veritas. Technical Report. Petroleum Safety Authority Norway (PSA). Material Risk - Ageing Offshore Installations. Report No. 2006-3496. 2010.

[24] K-t Ma, A Duggal, P Smedley, D L'Hostis, and H Shu. A Historical Review on Integrity Issues of Permanent Mooring Systems. In Proceedings of the Offshore Technology Conference (OTC 24025), Houston, USA, 2013.

[25] Tension Technology International. Examination and Investigation to Establish Cause of Polyester Rope Failure - Girassol Loading Buoy. Final Report for Single Buoy Moorings Inc. TTI report Ref: TTI-SJB-2002-185-R, 2003.

[26] P Jean, K Goessens, and D L'Hostis. Failure of Chains by Bending on Deepwater Mooring Systems. In Proceedings of the Offshore Technology Conference (OTC 17238), Houston, USA, 2005.

[27] SJ Banfield, NF Casey, and R Natraja. Durability of Polyester Deepwater Mooring Rope. In Proceedings of the Offshore Technology Conference (OTC 17510), Houston, USA, 2005.

[28] Strategic Initiative for Ocean Energy (SI Ocean). Ocean Energy: Cost of Energy and Cost Reduction Opportunities. 2013.

[29] Z Gao and T Moan. Mooring System Analysis of Multiple Wave Energy Converters in a Farm Configuration. In Proceedings of the 8th European Wave and Tidal Energy Conference, Uppsala, Sweden, 2009.

[30] J Gilmore, R Chou, and EH Zimmerman. Hurricane-Resistant Mooring System-Enabling Technology Through the Use of Synthetic Ropes. In Proceedings of the Offshore Technology Conference (OTC 20155), Houston, USA, 2009.

[31] RE Harris, L Johanning, and J Wolfram. Mooring systems for wave energy converters: A review of design issues and choices. In Proceedings of the 3rd International Conference on Marine 
Renewable Energy, Blyth, UK, 2004.

[32] Floating Power Plant A/S. P37 back for 4th offshore test phase. http://tinyurl.com/q6zr6cn, September 2013. [Accessed online: $27 / 05 / 2014]$.

[33] reNEWS. Scotrenewables floats Lashy plan. http://tinyurl.com/pfyfjrg, August 2014. [Accessed online: $14 / 08 / 2014]$.

[34] SD Weller, TJ Stallard, and PK Stansby. Experimental Measurements of the Complex Motion of a Suspended Axisymmetric Floating Body in Regular and Near-Focused Waves. Applied Ocean Research, 39:137-145, 2013.

[35] TJ Stallard, Weller SD, and PK Stansby. Limiting heave response of a wave energy device by draft adjustment with upper surface immersion. Applied Ocean Research, 8:282-289, 2009.

[36] J Fitzgerald and L Bergdahl. Including moorings in the assessment of a generic offshore wave energy converter: A frequency domain approach. Marine Structures, 21:23-46, 2008.

[37] L Johanning, GH Smith, and J Wolfram. Interaction Between Mooring Line Damping and Response Frequency as a Result of Stiffness Alteration in Surge. In Proceedings of the 25th International Conference on Offshore Mechanics and Arctic Engineering (OMAE2006-92373), Hamburg, Germany, 2006.

[38] Det Norske Veritas. Offshore Standard - Global performance analysis of deepwater floating structures. DNV-RP-F 205. 2009.

[39] DuPont. Innovation Starts, 2014. [Accessed online: $05 / 03 / 2014]$

[40] Vectran Fiber Inc. Vectran ${ }^{\circledR}$ Properties, 2010. [Accessed online: $05 / 03 / 2014]$.

[41] MC Kenny, JF Mandell, and FJ McGarry. The effects of sea water and concentrated salt solutions on fatigue of nylon 6,6 fibres. Journal of Materials Science, 20:2060-2070, 1985.

[42] DA Ruehle, C Perbix, M Castaeda, JR Dorgan, V Mittal, $\mathrm{P}$ Halley, and D Martin. Blends of biorenewable polyamide-11 and polyamide-6,10. Polymer, 54:6961-6970, 2013.

[43] C Lechat, AR Bunsell, and P Davies. Tensile and creep behaviour of polyethylene terephthalate and polyethylene naphthalate fibres. Journal of Materials Science, 46:528-533, 2011.

[44] American Petroleum Institute. Recommended Practice for Design, Manufacture, Installation and Maintenance of Synthetic Fiber Ropes for Offshore Mooring. Draft Second Edition. API RP 2SM. 2012.

[45] Det Norske Veritas. Offshore Standard - Offshore Fibre Ropes. DNV-OS-E303. 2013

[46] Parish, D and Johanning, L. Mooring Limb. United States Patent: PCT/IB2011/050206, 2012

[47] T Gordelier, D Parish, PR Thies, and L Johanning. A novel mooring tether for highly dynamic offshore applications; mitigating peak and fatigue loads via reduced and selectable axial stiffness. In Proceedings of the International Conference on Offshore Renewable Energy, Glasgow, UK, 2014.

[48] Det Norske Veritas. Offshore Service Specification - Certification of Tidal and Wave Energy Converters. DNV-OSS-213. 2012.

[49] The Carbon Trust. Guidelines on design and operation of wave energy converters. 2005.

[50] IEC. Marine energy - Wave, tidal and other water current converters - Part 10: The assessment of mooring system for marine energy converters. IEC-TS 62600-10 Ed.1.0 (In-Progress). 2015 .

[51] Det Norske Veritas. Offshore Standard - Design of Floating Wind Turbine Structures. DNV-OS-J103. 2013.

[52] M-Y Lee, P Devlin, and C-TT Kwan. Development of API RP 2SM for Synthetic Fiber Rope Moorings. In Proceedings of the Offshore Technology Conference (OTC 12178), Houston, USA, 2000.

[53] P Davies, F Grosjean, M François, K Salomon, P Baron, and D Trassoudaine. Synthetic Mooring Lines for Depths to 3000 Meters. In Proceedings of the Offshore Technology Conference (OTC 14246), Houston, USA, 2002.

[54] American Bureau of Shipping. Guidance Notes on the Application of Fiber Rope for Offshore Mooring. 2011.
[55] Bureau Veritas. Certification of Fibre Ropes for Deepwater Offshore Services. Guidance note: NI432DTOR01E. 2007.

[56] International Standards Organisation. Fibre ropes for offshore station keeping - Polyester. ISO 18692. 2007.

[57] Oil Companies International Marine Forum. Mooring Equipment Guidelines (MEG3). 2008.

[58] P Davies, S Weller, and L Johanning. Testing of synthetic fibre ropes. Deliverable 3.5.1 from the MERiFIC Project. Ifremer reference: RDT MS12-182, 2012.

[59] S Weller, P Davies, L Johanning, and Banfield S. Guidance on the use of synthetic fibre ropes for marine energy devices. Deliverable 3.5.2 from the MERiFIC Project. Ifremer reference: RDT CSM 13-232, 2013.

[60] Oil Companies International Marine Forum. Guidelines for the purchasing and testing of SPM hawsers. 2000.

[61] International Standards Organisation. Determination of single-end breaking force and elongation at break using constant rate of extension (CRE) tester. ISO 2062. 2009.

[62] SR Ghoreishi, P Cartraud, P Davies, and Messager T. Analytical modeling of synthetic fiber ropes subjected to axial loads. Part I: A new continuum model for multilayered fibrous structures. International Journal of Solids and Structures, 44(9):2924-2942, 2007.

[63] Cordage Institute. Test Method for Yarn-on-Yarn Abrasion, Wet and Dry. Test Method CI 1503-09. 2009.

[64] G Derombise, E Chailleux, B Forest, L Riou, N Lacotte, VL Van Schoors, and P Davies. Long-Term Mechanical Behavior of Aramid Fibers in Seawater. Polymer Engineering And Science, 51:1366-1375, 2011.

[65] SD Weller, P Davies, AW Vickers, and L Johanning. Synthetic Rope Responses in the Context of Load History: The Influence of Aging. Ocean Engineering, 96:192-204, 2015.

[66] E Chailleux and P Davies. Modelling the Non-Linear Viscoelastic and Viscoplastic Behaviour of Aramid Fibre Yarns. Mechanics of Time-Dependent Materials, 7:291-303, 2003.

[67] Det Norske Veritas. Recommended Practice. Environmental Conditions and Environmental Loads. DNV-RP-C205. 2010.

[68] PR Thies, L Johanning, and GH Smith. Towards component reliability testing for marine energy converters. Ocean Engineering, 34:1918-1934, 2011.

[69] F Cerveira, N Fonseca, and R Pascoal. Mooring system influence on the efficiency of wave energy converters. International Journal of Marine Energy, 3-4:65-81, 2013.

[70] KE Kaasen, $\mathrm{H}$ Lie, J Wu, E Falkenberg, V Ahjem, and K Larsen. Development of time domain model for synthetic rope mooring systems. In Proceedings of the 33rd International Conference on Ocean, Offshore and Arctic Engineering (OMAE2014-24180), San Francisco, USA, 2014.

[71] L Foulhoux, S Pennec, G Damy, and P Davies. Testing of a large diameter polyester rope offshore west Africa. In Proceedings of the 9th International Offshore and Polar Engineering Conference, Brest, France, 1999.

[72] Ayres, R. Characterizing polyester rope mooring installation damage, 2001. Technical Report to the U.S. Minerals Management Service and the Offshore Technology Research Center.

[73] E Chailleux and P Davies. A Non-linear Viscoplastic Viscoelastic Model for the Behaviour of Polyester Fibres. Mechanics of Time-Dependent Materials, 9:147-160, 2005.

[74] M François, P Davies, F Grosjean, and F Legerstee. Modelling of fibre rope load-elongation properties - Polyester and other fibres. In Proceedings of the Offshore Technology Conference (OTC 20846), Houston, USA, 2010.

[75] HS da Costas Mattos and FEG Chimisso. Modelling creep tests in HMPE fibres used in ultra-deep-sea mooring ropes. International Journal of Solids and Structures, 48(1):144-152, 2011.

[76] MS Overington and CM Leech. Modelling Heat Buildup In Large Polyester Ropes. International Journal of Offshore and Polar Engineering, 7(1), 1997.

[77] JF Flory, CM Leech, SP Banfield, and DJ Petruska. Computer Model to Predict Long-Term Performance of Fiber Rope Moor- 
ing Lines. In Proceedings of the Offshore Technology Conference (OTC 17592), Houston, USA, 2005.

[78] W Huang, H Liu, Y Lian, and L Li. Modelling nonlinear creep and recovery behaviours of synthetic fibre ropes for deep-water moorings. Applied Ocean Research, 39:113-120, 2012.

[79] TD Vu, D Durville, and P Davies. Finite element simulation of the mechanical behaviour of synthetic braided ropes and validation on a tensile test. International Journal of Solids and Structures, 58:106-116, 2015.

[80] P Davies, E Chailleux, A Bunsell, F Grosjean, and M François. Prediction of the long term behavior of synthetic mooring lines. In Proceedings of the Offshore Technology Conference (OTC 15379), Houston, USA, 2003.

[81] MP Vlasblom, J Boesten, S Leite, and P Davies. Development of HMPE Fiber for Permanent Deepwater Offshore Mooring. In Proceedings of the Offshore Technology Conference (OTC 23333), Houston, USA, 2012.

[82] S Backer, FJ McGarry, and JH Williams. Deterioration of Synthetic Fiber Rope During Service, 1981.

[83] JD Otten and S Leite. Thunder Hawk Mooring Rope Particle Ingress, Break, and Fatigue Testing. In Proceedings of the Offshore Technology Conference (OTC 24080), Houston, USA, 2013

[84] D Petruska, H Wylie, J Geyer, and S Rijtema. Mad Dog polyester mooring installation. In Proceedings of the 16th Annual Deep Offshore Technology (DOT) Conference, New Orleans, USA, 2004.

[85] RLM Bosman. On the Origin of Heat Build-up in Polyester Ropes. In Proceedings of OCEANS '96 MTS/IEEE, Fort Lauderdale, USA, 1996.

[86] S Abrate, R Dooley, R Kaste, G Thibault, and W Millette. Nonlinear dynamic behavior of parachute static lines. Composite Structures, 61:3-12, 2003.

[87] Mason, AJ. An Experimental Investigation of Damaged Arresting Gear Tapes for the Langley Aircraft Landing Dynamics Facility. NASA/TM-1999-209839 . 1999.

[88] AJ McLaren. Design and performance of ropes for climbing and sailing. Proc. IMechE Vol. 220 Part L: J. Materials: Design and Applications, 2006.

[89] Tension Technology International. Heidrun RPN - Review Operating Limit and Feasibility Net Replacement. Report for Statoil. TTI report Ref: TTI-SJB-2006-389-R, 2006.

[90] Tension Technology International. Deepstar TLM Polyester Ropes Pathological Studies Report, 1999.
[91] Det Norske Veritas. Offshore Service Specification - Rules for classification of Floating Production, Storage and Loading Units. DNV-OSS-102. 2010.

[92] American Petroleum Institute. Recommended Practice - Inservice Inspection of Mooring Hardware for Floating Structures. API RP 2I. 2008.

[93] Cordage Institute. International Guideline Fiber Rope Inspection and Retirement Criteria Guidelines to Enhance Durability and the Safer Use of Rope. CI 2001-04. 2001.

[94] Det Norske Veritas. Recommended Practice - Damage Assessment of Fibre Ropes for Offshore Mooring. DNV-RP-E304. 2005.

[95] European Marine Energy Centre. Guidelines for Reliability, Maintainability and Survivability of Marine Energy Conversion Systems. 2009.

[96] D Barton Smith and JG Williams. Direct Measurement of Large Strains in Synthetic Fiber Mooring Ropes Using Polymeric Optical Fibers. In Proceedings of the Offshore Technology Conference (OTC 14242), Houston, USA, 2002.

[97] G Rebel, CR Chaplin, C Groves-Kirby, and IML Ridge. Condition monitoring techniques for fibre mooring ropes. Insight, the Journal of The British Institute of Non-Destructive Testing, 42:384-390, 2000.

[98] N O'Hear. Optical Scanning Apparatus for Ropes. Nondestructive Test Monitoring System. In Proceedings of the OCEANS 2003 conference, San Diego, USA, 2003.

[99] JH Williams, J Hainsworth, and SS Lee. Acoustic-Ultrasonic Nondestructive Evaluation of Double-Braided Nylon Ropes Using the Stress Wave Factor. Fiber Science and Technology, 21:169-180, 1984.

[100] Tension Technology International, AWS, Ocean Power Technologies, Bridon, Promoor and Ecosea. Mooring systems, anchors and intermediate components (MOSAIC), study. Funded by Carbon Trust, 2007.

[101] Department for Trade and Industry. Decommissioning of Offshore Renewable Energy Installations under the Energy Act 2004. Guidance Notes for Industry. 2006.

[102] McIntyre, JE and Richards, AF and East, AJ and Cox, R and Mather, RR. Synthetic fibres: nylon, polyester, acrylic, polyolefin. Woodhead Publishing Limited, Cambridge, UK, 2005.

[103] Lankhorst Euronete. News, 2014. [Accessed online: 05/03/2014]. 